\title{
Astım tedavisinde kullanılan inhaler kortikosteroidlerin diabetes mellitus kontrolüne olan etkisi
}

\section{The effect of inhaled corticosteroids in treatment of asthma on the control of diabetes mellitus}

\author{
Fatih Üzer ${ }^{\mathbb{D}}$, Fatih Burak Alparslan² ${ }^{\mathbb{D}}$, Melahat Akdeniz ${ }^{\mathbb{D}}$,Ömer Özbudak ${ }^{3} \mathbb{D}$ \\ 1 Kastamonu Devlet Hastanesi, Göğüs Hastalıkları, Kastamonu \\ ${ }^{2}$ Akdeniz Üniversitesi Tıp Fakültesi Hastanesi, Aile Hekimliği Anabilim Dalı, Antalya \\ ${ }^{3}$ Akdeniz Üniversitesi Tıp Fakültesi Hastanesi, Göğüs Hastalıkları Anabilim Dalı, Antalya
}

Öz.

Amaç: Çalışmamızda astım tanılı diyabet hastalarında inhaler kortikosteroidlerin diyabet kontrolü üzerine olan etkisini araştırmayı amaçladık.

Materyal ve Metot: Calıșmamız retrospektif vaka kontrol çalıșmasıdır. Çalıșmaya 1 Ocak 2016-1 Ocak 2017 tarihleri arasında Akdeniz Üniversitesi Tıp Fakültesi Hastanesi Aile Hekimliği Polikliniği'ne başvuran diabetes mellitus tanılı hastalar ile Göğüs Hastalıkları Polikliniği'ne başvuran astım tanıı diabetes mellitus hastaları alındı. Herhangi bir nedenle sistemik steroid kullanan hastalar, düzenli ilaç kullanmayan diyabet tanılı hastalar, diyabetik ketoasidoz ile başvuran hastalar, son 1 yılda oral steroid kullanılmayı gerektiren astım atağı geçiren hastalar çalışma dışı bırakıldı.

Bulgular: Çalışmaya ortalama yaşı 59,1 $\pm 9,6$ olan, $44(\% 31,9)$ erkek, 94 (\%68,1) kadın toplam 138 hasta dâhil edildi. Çalışmaya alınan hastaları \%68,1 (94)'i astım tanısı olmayan diabetes mellitus tanılı hasta iken, \%31,9 (44)'u astım tanısı olan diabetes mellitus tanııı hasta idi. Astım tanısı olmayan grup ile astım tanısı olan grup karşılaştııılığında kan glukoz $(p<0.006)$ seviyeleri ve nöropati $(p<0.001)$ görülme sıklğı astım tanısı olan grupta istatistiksel anlamlı düzeyde yüksek iken, nefropati $(p<0.023)$ görülme sıklı̆ı astım tanısı olmayan grupta istatistiki olarak anlamlı düzeyde daha yüksek bulunmuştur. Çalışmamızda her iki grup arasında yaş, hemoglobin düzeyleri ve glikozillenmiş hemoglobin düzeyleri bakımından istatistiki anlamlı farklllık tespit edilmedi.

Sonuç: Sonuç olarak düşük-orta doz inhaler kortikosteroid kullanımı astım tanısı olan diabetes mellitus hastalarında glikozillenmiş hemoglobin düzeylerinde değişikliğe neden olmazken, kan glukoz seviyesinde ve diyabete bağlı komplikasyonlardan nöropati riskinde artışa neden olabilir.

Anahtar kelimeler: Astım, Diabetes mellitus, İnhaler kortikosteroid

Abstract

Background: We aimed to investigate the effect of inhaled corticosteroids on diabetes control in asthma-diagnosed diabetic patients.

Methods: Our study is a retrospective case-control study. Between January 1, 2016 and January 1, 2017, patients with diabetes mellitus who visited Family Medicine Outpatients of Akdeniz University Medical Faculty Hospital and patients with diabetes mellitus diagnosed with asthma who visited Chest Diseases Outpatients were enrolled. Patients who used systemic steroids for any reason, diabetes mellitus patients who did not take regular medication, patients who diagnosed as diabetic ketoacidosis, and patients who needed oral steroids for asthma exacerbation within the last year were excluded from the study.

Results: A total number of 138 patients (mean age 59.1 \pm 9.6$), 44$ (31.9\%) male and 94 (68.1\%) female were included in the study. $68.1 \%$ (94) of the patients diagnosed as diabetes mellitus without asthma diagnosis, while $31.9 \%$ (44) were DM diagnosed with asthma diagnosis. The frequency of high blood glucose $(p<0.006)$ and neuropathy $(p<0.001)$ were significantly higher in the asthmatic group compared to the non-asthmatic group, whereas the incidence of nephropathy ( $p$ $<0.023$ ) were found to be significantly higher in non-asthmatic group. There was no statistically significant difference in age, hemoglobin levels and glycated hemoglobin levels between the two groups in our study

Conclusions: In conclusion, the use of low-to-moderate inhaled corticosteroids may cause an increase in the risk of neuropathy from diabetic complications and higher blood glucose levels, while not altering glycated hemoglobin levels in asthmatic patients with diabetes mellitus.

Keywords: Asthma, Diabetes Mellitus, Inhaled corticosteroids

\section{Sorumlu Yazar I \\ Corresponding Author}

Dr. Fatih Üzer

Kastamonu Devlet Hastanesi, Göğüs Hastalıkları Kliniği

Tel: +90 5544811422

e-mail: uzerfatih@gmail.com

Geliş tarihi / Received: 23/04/2019

Kabul tarihi / Accepted: 01/08/2019

DOI: $10.35440 /$ hutfd. 557202 


\section{Giriş}

Astım toplumun \%2-17'sini etkileyen kronik inflamatuvar bir akciğer hastalığı olup tedavisinde kullanılan en temel ilaçlar inhaler kortikosteroidlerdir (IKS). İKS'ler astımda esas olarak antiinflamatuvar özellikleri için kullanılmaktadır. Ancak yüksek dozlarda ve uzun dönem kullanılmaları sonucu kan şekeri regülasyonunda bozulma, katarakt, glokom, osteoporoz, adrenal yetmezlik görülebilir (1).

Diabetes mellitus (DM), insülin eksikliği ya da insülin etkisindeki defektler nedeniyle organizmanın karbonhidrat, yağ ve proteinlerden yeterince yararlanamadığı, sürekli tıbbi bakım gerektiren, kronik bir metabolizma hastalığıdır (2). Hastalığın, akut komplikasyon riskini azaltmak ve uzun dönemde tedavisi pahalı olan kronik sekellerinden korunmak için sağlık çalışanları ve hastaların sürekli eğitimi şarttır.

Diabetes mellitus ve astım toplumda en sık görülen kronik hastalıkların başında gelmektedir. Her iki hastalığın kontrol altında olması halk sağıı̆̆ açısından önemlidir. Astım atağında sık kullanılan oral kortikosteroidlerin kan glukoz seviyelerine olan etkileri iyi bilinmektedir (3-6). Ancak IKS kullanan hastalarda diyabet kontrolü ile ilgili veriler tartışmalıdır (7-11). Kortikosteroidlerin inhaler olarak kullanılmasının oral ya da diğer sistemik kullanımlara göre güvenli olduğunu belirten çalışmalar olmakla birlikte, yüksek dozda kullanımın diyabet regülasyonunu bozabileceğini belirten yayınlar da vardır $(7,12)$. Çalışmamızda astım tanılı diyabet hastalarında İKS'lerin diyabet kontrolü üzerine olan etkisini araştırmayı hedefledik.

\section{Materyal ve Metot}

Çalışmamız retrospektif vaka kontrol çalışmasıdır. Çalışmaya 1 Ocak 2016-1 Ocak 2017 tarihleri arasında Akdeniz Üniversitesi Tıp Fakültesi Hastanesi Aile Hekimliği Polikliniği'ne başvuran DM tanılı hastalar ile Göğüs Hastalıkları Polikliniği'ne başvuran astım tanılı DM hastaları alındı. DM ve astım birlikteliği olanlar çalışma grubu, astım tanısı olmayan DM tanılı hastalar kontrol grubu olarak kabul edildi. Çalışmaya dahil edilen astım hastalarının tanısı Global Initiative for Asthma (GINA) kılavuzuna göre konmuştu (13). İnhaler ilaç düzenlemesi GINA rehberi temel alınarak göğüs hastalıkları uzmanı tarafından yapıldı. Bu kılavuza göre hışıltılı solunum, nefes darlığı, öksürük, göğüste sıkışma hissi gibi solunumsal semptomları olan hastalarda spirometri ile değişken hava akımı kısıtlanması gösterilen hastalar astım olarak kabul edildi. Her iki gruptaki hastalar hastane otomasyon sisteminden tarandı; DM için diabetik ketoasidoz atağı geçirmedikleri, astım içinse astım atağı geçirmedikleri stabil dönemde bakılmış olan laboratuar tetkikleri veri formuna kaydedildi. Astımlı hastada alevlenme, ilerleyen nefes darlığı, öksürük, hırıtı veya göğüste sıkışma hissi belirtilerinin ortaya çıkışı, buna solunum fonksiyonlarında azalma ve klinik düzelme için sistemik steroide intiyaç duyulması olarak tanımlandı. Plazma glukoz
$>250 \mathrm{mg} / \mathrm{dl}$, arteriyel $\mathrm{pH}<7.30$, serum bikarbonat $<15$ $\mathrm{mEq} / \mathrm{l}$ ve orta/ağır derecede ketonüri ve ketonemi varlığı ise diyabetik ketoasidoz olarak tanımlandı. Çalışma için bakılan laboratuar tetkikleri glikozillenmiş hemoglobin $(\mathrm{HbA} 1 \mathrm{c})$, açlık kan glukoz düzeyleri, tam idrar tetkikleri ve kreatinin düzeyleri forma kaydedildi. Ayrıca hasta dosyasından bakılarak diyabete bağlı komplikasyonlar ile DM için kullandığı ilaçların sayısı ve çeşidi veri formuna kaydedildi. Çalışmaya 18 yaşından büyük DM tanılı tüm hastalar alındı. Herhangi bir nedenle sistemik steroid kullanan hastalar, düzenli ilaç kullanmayan DM tanılı hastalar, diyabetik ketoasidoz ile başvuran hastalar, son 1 yılda oral steroid kullanılmayı gerektiren astım atağı geçiren hastalar çaıışma dışı bırakıldı. Hastaların diabetik komplikasyonları dosya sisteminde takip eden ilgili hekimin notuna göre belirlendi.

Bu çalışmanın etik kurulu Akdeniz Üniversitesi Tıp Fakültesi Klinik Araştırmalar Etik Kurulu (31/05/2017 tarihli, 323 karar nolu) tarafindan alınmıştır.

Veriler PASW 20 (SPSS/IBM, Chicago, IL, USA) kullanılarak analiz edildi. Örneklemi tanımlamak için frekans dağıIımı, ortalama, standart sapma gibi tanımlayıcı istatistikler kullanıldı. Parametrik test varsayımlarının sağlandığı durumlarda bağımsız iki grup ortalamalarının farkı "Student $t$ testi" ile araştıııldı. Parametrik test varsayımlarının sağlanmadığı durumlarda ise bu testlerin parametrik olmayan alternatifleri, "Mann-Whitney U" ve "Kruskall Wallis" testleri kullanıldı. Kategorik veriler ise "ki-kare anlamlılık testi" ile incelendi.

Analizlerde farklııkların belirlenmesi için \% 95 anlamlıık düzeyi (ya da $\alpha=0.05$ hata payı) kullanıldı.

\section{Bulgular}

Çalışmaya rastgele seçilmiş ortalama yaşı $59,1 \pm 9,6$ olan, $44(\% 31,9)$ erkek, $94(\% 68,1)$ kadın toplam 138 hasta dahil edildi. Çalışmaya alınan hastaların $\% 68,1$ (94)'i astım tanısı olmayan DM tanılı hasta iken, \%31,9 (44)'u astım tanısı olan DM tanılı hasta idi. Her iki grubun cinsiyet ve yaş dağıımı benzerdi (Tablo 1). Hastaların temel özellikleri Tablo 1'de, diyabet komplikasyonları ve kullanılan ilaçlar Tablo 2'de verilmiş̧ir. Astım tanısı olan hastalarımızın \%6,8 (3)'i düşük doz, \%93,1 (41)'i orta doz İKS kullanmakta olup, yüksek doz IKSS kullanan hastamız yoktu. ÇaIışmaya dahil edilen hastalardan üçü sadece IKS, 18'i IKS+uzun etkili beta2 agonist, diğer 23 hasta ise IKS+uzun etkili beta2 agonist +montelukast kullanıyordu. Astımı olan diyabetiklerde astım tanı süresi 12,5 $\pm 9,6$ (1-40) yıl, DM tanı süresi ortalama $8,2 \pm 5,2(1-23)$ yll, sadece DM olan hastalarda ise DM tanı süresi $8,3 \pm 7,5$ (1-30) olarak tespit edildi. Astım tanısı olan DM hastalarında en sık görülen ek hastalıklar \%70,4 (31) hipertansiyon ve \%30,0 (15) hipotiroidi iken sadece diyabeti olan hastalarda en sık görülen ek hastalıklar \%58,5 (55) hipertansiyon, \%43,1 (19) hipotiroidi olarak saptandı. Astım ve diyabet ilaçları dışında en 
sık kullanılan ilaçlar her iki grupta da antihipertansifler (sıklık sırasına göre; Anjioconverting enzim inhibitörleri, Angiotensin II reseptör blokerleri, Kalsiyum kanal blokerleri, Betablokerler, Diüretikler (düşük doz)), antitiroid ilaçlar (levotiron) ve proton pompa inhibitörleri idi. Astımı olan diyabet hastalarının soygeçmişinde en sık görülen hastalıklar; $\% 29,5$ (13) DM, \%15,9 (7)'ar astım ve koroner arter hastalığı, \%11,3 (5)'er hipertansiyon ve malignite iken, astımı olmayan DM hastalarının soygeçmişinde en sık görülen hastalıklar; \%54,2(51) DM, \%29,7 (28) hipertansiyon, \%19,1 (18)'er koroner arter hastalığı ve malignite idi. Astım tanısı olmayan DM tanılı hastalar ile astım tanısı olan DM tanılı hastalar karşılaştırıldığında kan glukoz $(p<0.006)$ seviyeleri ve nöropati $(p<0.001)$ görülme sıklığı astım tanısı olan DM hastalarda istatistiksel anlamlı düzeyde yüksek iken, nefropati ( $p<0.023)$ görülme sıkığı astım tanısı olmayan grupta istatistiki olarak anlamlı düzeyde daha yüksek bulunmuştur. Çalışmamızda her iki grup arasında yaş, hemoglobin düzeyleri ve $\mathrm{HbA} 1 \mathrm{c}$ düzeyleri bakımından istatistiki anlamlı farklılık tespit edilmedi (Tablo 3-4).

Tablo 1. Hastaların temel özellikleri

\begin{tabular}{llll}
\hline Özellik & Ortalama & $\begin{array}{l}\text { Standart } \\
\text { Sapma }\end{array}$ & $\begin{array}{l}\text { Dağılım } \\
\text { Aralığı }\end{array}$ \\
\hline $\begin{array}{l}\text { Yaş (yıl) } \\
\text { Hemoglobin }\end{array}$ & 59,1 & 9,6 & $21-87$ \\
(mg/dL) & 13,0 & 1,5 & $8,09-17,00$ \\
HbA1c & & & \\
Glukoz & 6,5 & 0,9 & $5,00-10,20$ \\
Kreatinin & 121,5 & 36,9 & $78-297$ \\
\hline
\end{tabular}

Tablo 2. Tüm olgularda diyabet komplikasyonları ve kullanılan ilaçlar

\begin{tabular}{ll}
\hline & $\mathbf{n}(\%)$ \\
\hline Proteinüri & $17(\% 12,3)$ \\
Glukozüri & $3(\% 2,2)$ \\
Nefropati & $20(\% 14,5)$ \\
Nöropati & $15(\% 10,9)$ \\
Retinopati & $5(\% 3,6)$ \\
Insülin & $24(\% 17,4)$ \\
Oral anti-diyabetik & $114(\% 82,6)$ \\
\hline
\end{tabular}

$\underline{\text { Tablo 3. Her iki grubun sürekli değişkenlerinin karşılaştırılması }}$

\begin{tabular}{llll}
\hline & DM (n:94) & $\begin{array}{l}\text { Astım+DM } \\
\text { (n:44) }\end{array}$ \\
\hline & ortalama \pm Ss & ortalama \pm Ss & p \\
\hline Yaş (yıl) & $62,3 \pm 9,4$ & $57,6 \pm 9,4$ & 0.950 \\
DM yaşı & $8,3 \pm 7,5$ & $8,2 \pm 5,2$ & 0.936 \\
(yıl) & & & \\
Hb (mg/dL) & $12,6 \pm 1,7$ & $13,2 \pm 1,4$ & 0.268 \\
Hba1c & $6,6 \pm 0,9$ & $6,5 \pm 0,9$ & 0.205 \\
$\begin{array}{l}\text { Kreatinin } \\
\text { (mg/dL) }\end{array}$ & $0,78 \pm 0,16$ & $0,77 \pm 0,21$ & 0.570 \\
$\begin{array}{l}\text { Glukoz } \\
\text { (mg/dL) }\end{array}$ & $112,7 \pm 20,8$ & $125,7 \pm 41,8$ & 0.006 \\
\hline DM: Diabetes Mellitus, Ss:Standart sapma &
\end{tabular}

Harran Üniversitesi Tıp Fakültesi Dergisi (Journal of Harran University Medical Faculty) 2019;16(2):295-299.

DOI: 10.35440/hutfd.557202
Tablo 4. Her iki grubun kategorik verilerinin karşılaştırılması

\begin{tabular}{llll}
\hline & DM (n:94) & $\begin{array}{l}\text { Astım+DM } \\
\text { (n:44) }\end{array}$ & \\
\hline & $\mathbf{n}(\%)$ & $\mathbf{n ~ ( \% )}$ & $\mathbf{p}$ \\
\hline Proteinüri & $12(12,76)$ & $5(11,36)$ & 0.815 \\
Glukozüri & $2(2,12)$ & $1(2,27)$ & $y . v$ \\
Nefropati & $12(12,76)$ & $8(18,18)$ & 0.4 \\
Nöropati & $5(5,31)$ & $10(22,72)$ & 0.002 \\
Retinopati & $2(2,12)$ & $3(6,81)$ & $y \cdot v$ \\
Insülin & $14(14,89)$ & $10(22,72)$ & 0.258 \\
Kadın & $63(67,02)$ & $31(70,45)$ & 0.687 \\
\hline
\end{tabular}

DM: Diabetes Mellitus, Ss:Standart sapma, y.v: yetersiz veri

\section{Tartışma}

Diyabetli hastalarda komorbidite varlığı sık görülmekte, en az yarısında üç veya daha fazla komorbid kronik hastalık bulunmaktadır (14). Komorbidite varlığı hastalığın yönetimini zorlaştırmakta ve sağlık sistemine olan maliyetini arttırmaktadır. Astım diyabetik hastalarda görülen komorbiditelerden biridir. İlk yapılan çalışmalarda Tip 2 DM tanılı hastalarda astım görülme oranı \%0,3-1,5 arasında iken, daha yeni çalışmalarda bu oran \%13 civarındadır (15-18). Tip 1 DM tanılı çocuklarda yapılan çalışmalarda astım görülme oranı $\% 5,7$ tespit edilmiştir (19).

Inhaler kortikosteroidler, her yaşta astım tedavisinin temel dayanak noktasıdır. IKS'lerin geniş antiinflamatuvar aktivitesi vardır. Alerjenlere karşı hava yolu aşırı duyarlıı̆̆ında altta yatan havayolu inflamasyonunu kontrol ederler. İKS mortaliteyi ve hastaneye yatma riskini uzun vadede azalttığı gösterilen tek astım ilacıdır $(1,13)$. Terapötik yararın çoğu flutikazon $200 \mathrm{mg}$ / gün veya eşdeğeri gibi düşük dozlarda elde edilirken, yan etkiler dozun artmasıyla birlikte doğrusal bir şekilde artmaktadır (20). Yüksek doz IKS kullanımında akciğerlerden emilim sonucu sistemik yan etki meydana gelebilir $(1,13,20-22)$. Bu nedenle, mümkün olan en düşük etkili dozun kullanılması ve astımı birkaç ay boyunca iyi kontrol edilen hastalarda dozun daha da düşürülmesi önemlidir $(1,13,21)$. Oral kortikosteroid uygulaması sıklıkla diyabetin kötüleşmesine neden olur, ancak IKS kullanımı ile ilişkili diyabetik kişilerde glukoz homeostazında klinik olarak önemli değişiklikler hakkında çok az veri vardır. Çalışmamızda IKS kullanan hastalarda HbA1c'nin kontrol grubuna göre istatistiksel anlamlı düzeyde artmadığı, ancak kan glukoz düzeyinin istatistiki anlamlı düzeyde yüksek olduğu tespit edildi. Faul ve arkadaşları (22) tarafından yapılan prospektif plasebo kontrollü, çift kör bir çaIışmada çalışmamız ile aynı sonuç bulunmuştur. Faul ve arkadaşlarının çalışmasında $\mathrm{HbA} 1 \mathrm{c}^{\prime}$ nin normal, kan glukoz seviyesinin yüksek olması çalışma süresinin kısalığına (42 gün) bağlanmıştır. Çalışmamızda ortalama astım tanı süresi 12,5 yıl olmasına rağmen böyle bir sonuç ortaya çıkması ilginçtir.

1990'lı yapılan çalışmalarda İKS kullanımı ve DM riski arasında bir ilişki bulunamamıştır. Bu durum o dönemde düşük doz İKS kullanılmasına bağlanmıştır. Aynı dönemde 
diyabet riski taşıyan yaşı KOAH hastalarında IKKS'ler daha az yaygın kullanılmıştır (12,24). 2007 yılında Kanada'da 388.000 kişinin katılıı̆ı geniş çaplı çalışmada İKS kullanan hastalarda diyabet regülasyonunda bozulma ve yeni tanı diyabet riskinde artış olduğu tespit edilmiştir (12). Bu çalışmada diyabet regülasyonunda bozulma Flutikazonun günlük 1000 mg veya daha fazlasına eşdeğer yüksek IKS dozlarında görülmüştür. Lieberman ve arkadaşları (5) tarafından yapılan çalışmada ise IKS kullanan astım hastaları ile kullanmayan astım hastaları karşılaştııılığında IKS kullanan grupta kilo artışı, sıvı retansiyonu, kolay morarma, hipertansiyon, DM, epigastrik şikayetleri ve elektrolit imbalansı daha fazla görülmüştür.

Bu bulguların yanında literatürde IKS'lerin DM riskini arttırmadığını gösteren çalışmalar da vardır. Dendukuri ve arkadaşları (8) tarafından 2002 yılında ve Mattishent (9) tarafından 2014 yılında yapılan çalışmalarda IKSS'lerin DM riskini artırmadığı tespit edilmiştir. Bizim çalışmamızda IKS'ye bağlı DM gelişip gelişmediğine bakılmadı. Ancak astımı olan diyabet hastalarının ortalama 12,5 yıldır astım, 8.5 yıldır da DM tanılı olduğu saptandı. Bu bulgu bazı hastalarda IKSS'nin diyabet tanısına katkıda bulunmuş olabileceğini düşündürmektedir. Diyabet komplikasyonlarından nöropatinin IKS kullanan grupta istatistiki olarak anlamlı düzeyde yüksek olduğu sonucuna varılırken, diğer komplikasyonların her iki grup arasında istatistiki anlamlı düzeyde fark saptanmadı.

Oral kortikosteroidler, akciğer fonksiyonlarını ve hipoksemiyi iyileştirmek ve iyileşme süresini kısaltmak için alevlenmelerin kısa vadeli tedavisi için önerilir, ancak yan etkilerinden dolayı kronik olarak önerilmez (14). Kortikosteroid kullanımı ile kan glikoz düzeylerinde doza bağlı bir artış ve diyabet progresyonu riskinde artışa bağlı olarak, kortikosteroidler diyabetli hastalarda önerilmemektedir $(1,4-5,13)$. Yapılan çalışmalara göre İKS'lerin \%4-60'। akciğerlere ulaşmaktadır. IKS dozunun akciğerlere iletilen kısmı arzu edilen farmakolojik etkiyi gösterir. Hava yollarına ulaşan dozun önemli bir kısmı daha sonra pulmoner damar yapıları aracılığıyla sistemik dolaşıma absorbe edilebilir (21). Geri kalan kısmı ise gastrointestinal sistemden sistemik dolaşıma geçmektedir. Gastrointestinal kanal tarafından absorbe edilen ve karaciğerdeki ilk geçiş metabolizması (first pass metabolism) tarafından inaktive edilmekten kurtulan ilaç değişikliğe uğramadan sistemik dolaşıma girer ve olasilıkla ekstra pulmoner yan etkilere neden olur (21). Sistemik dolaşıma geçen kortikosteroid pankreatik beta hücrelerin fonksiyonunu bozarak insülin salıımını azaltabilir (4). Yüksek doz İKS kullanılması durumunda akciğerden emilerek ya da gastrointestinal sistemden emilerek sistemik dolaşıma geçen kortikosteroid diyabet regülasyonunda bozulmalara neden olabilir.

Diabetes mellitusta, hipergliseminin şiddeti mikrovasküler komplikasyonlar ile ilişkilidir. Genel bir kural olarak, $\mathrm{HbA} 1 \mathrm{c}$ (normal bireylerin $\mathrm{HbA} 1 \mathrm{c}<\% 6$ olması), önceki $4 \pm 12$ hafta boyunca ölçülen ortalama kan glikozu seviyeleri ile iyi korelasyon gösterir. IKSS'lerin diyabet regülasyonunu bozabileceğini bildiren ilk çalışmada, yüksek doz (1000 mg/gün) flutikazonun HbA1c seviyesinde yükselmeye ve glukozüriye neden olduğu görülmüş (7). Ancak bizim çalışmamızda her ne kadar çalışmaya alınan hasta sayısı az olsa da iki grup arasında istatistiki anlamlı farklılık tespit edilmedi. Bu durum hastalarımızın düşük-orta doz IKS kullanmasına bağlı olabilir.

Kortikosteroidler, insülin salgılanmasını azaltarak, insülin direncini artırarak ve karaciğerde glikoneogenezisi uyararak hiperglisemiye yol açar $(4,10,14)$. Kortikosteroidlerin, insülin direncine yol açan, insülin sinyal ağı içindeki bir takım basamakları inhibe ettiği gösterilmiştir. Bunlar, artmış proteoliz, lipoliz ve serbest yağ asidi üretimini içerir ve bu da insülin direncine katkıda bulunur. Kortikosteroidler aynı zamanda doğrudan hepatik glikoneogenezi artırabilir, bu da hiperglisemiye yol açar (24). Ancak bizim çalışma astımı olan diyabet hastaları ile astımı olmayan diyabet hastaları arasından insülin kullanma sıklığı açısından istatistiki anlamlı farkılık tespit edilemedi. Bunun nedeninin çalışmamızdaki hastaların önemli bir kısmının düşük-orta doz IKSS kullanması, bunun yanında yüksek doz IKSS kullanan hastamızın hiç olmamasına bağlı olabilir.

Caughey ve arkadaşları (14) her ne kadar kortikosteroidlerin (hem oral hem inhaler) diyabet üzerine olumsuz etkileri sadece yüksek dozlarda belirgin olsa da bu hasta populasyonunda kan glikoz düzeyinin yakından izlenmesi gerektiğini bildirmişlerdir. Ayrıca bu grup hastada (yüksek doz kortikosteroid kullanan) inhaler tedaviye başladıktan 4-8 hafta sonra tedavi etkinliğinin gözden geçirilmesi gerektiğini ve eşlik eden diyabeti olan hastalarda yüksek doz IKS'nin düzenli kullanılmasından kaçınıIması gerektiğini ifade etmişlerdir.

Diyabet komplikasyonlarının dosya bilgilerinden bakılmış olması ve hasta sayısının, özellikle yüksek doz IKKS kullanan hasta sayısının az olması çalışmanın en önemli kısıtIılıklarıdır.

Sonuç olarak düşük-orta doz İKS kullanımı astım tanısı olan diabetes mellitus hastalarında $\mathrm{HbA} 1 \mathrm{c}$ düzeylerinde değişikliğe neden olmazken, kan glukoz seviyesinde ve diyabete bağlı komplikasyonlardan nöropati riskinde artışa neden olabilir. Çalışmanın daha iyi planlanmış şekilde ve yeterli sayıda düşük-orta-yüksek doz IKS kullanan hastalarda yapılması yararlı olacaktır.

\section{Kaynaklar}

1. Türk Toraks Derneği Astım Allerji Çalışma Grubu. Turk Thorac J 2016 (Supplement 1).5-95

2. Satman I, İmamoğlu Ş, Yılmaz C, Akalın S, Salman S, Dinççağ N ve Diyabetes Mellitus Çalışma ve Eğitim Grubu. TEMD Diyabetes Mellitus ve Komplikasyonlarının Tanı, Tedavi ve İzlem Kılavuzu2017. 9. Baskı. Ankara: Bayt Matbaacılık; 2017.s.15.

3. Sullivan PW, Ghushchyan VH, Globe G, Schatz M, Oral Corticosteroid Exposure and Adverse Effects in Asthma, Journal of Allergy and Clinical Immunology 2018; 141(1):110-116. 
4. Schacke $\mathrm{H}$, Docke $\mathrm{W}$, Asadullah $\mathrm{K}$. Mechanisms involved in the side effects of glucocorticoids. Pharmacology \& Therapeutics 2002; 96:23-43.

5. Lieberman $P$, Patterson $R$, Kunske R. Complications of long-term steroid therapy for asthma. J. Allergy Clin Immunol 1972; 49:329336

6. Skorodin MS. Pharmacotherapy for Asthma and Chronic Obstructive Pulmonary Disease. Arch Intern Med 1993; 153:814-828

7. Faul JL, Torney W, Torney V, Burke C. High dose inhaled corticosteroids and dose dependent loss of diabetic control. Brith Med Journal 1998; 317:1491.

8. Dendukuri N, Blais L, LeLorier J. Inhaled corticosteroids and the risk of diabetes among the elderly. Br J Clin Pharmacol. 2002; 54:5964.

9. Mattishent $K$, Thavarajah M, Blanco $P$, Gilbert $D$, Wilson AM, Loke YK. Meta-Review: Adverse Effects of Inhaled Corticosteroids Relevant to Older Patients. Drugs. 2014; 74:539-547.

10. O'Byrne PM, Rennard S, Gerstein S, Radner F, Peterson S, Lindberg $B$ et al. Risk of new onset diabetes mellitus in patients with asthma or COPD taking inhaled corticosteroids. Respiratory Medicine. 2012; 106:1487-1493.

11. Barnes PJ. Inhaled Corticosteroids in COPD: A Controversy. Respiration. 2010; 80:89-95.

12. Suissa $S$, Kezouh A, Ernst P. Inhaled Corticosteroids and the Risks of Diabetes Onset and Progression. Am J Med. 2010;123:10011006.

13. GINA. 2016-Pocket Guide for Asthma Management and Prevention, GINA Foundation, 2016. Available at: nasthma.org/wp-content/uploads/2016/05/WMS-GINA2016-main-Pocket-Guide.pdf

14. Caughey GE, Preiss AK, Vitry Al, Gilbert AL, Roughead EE. Comorbid Diabetes and COPD. Diabetes Care. 2013; 36:3009-3013.

15. Helander E. Asthma and Diabetes. Acta Med Scand. 1958; 162:165-174.

16. Themeli $Y$, Ibro M, Dyrmishi L, Klosi J. Prevalence of bronchial asthma in patients with type 2 diabetes mellitus. Endocrine Abstracts. 2014; 35;355

17. Heck S, Al-Shobash A, Rapp D, Le DD, Omlor A, Bekhit A et al. High probability of comorbidities in bronchial asthma in Germany. NPJ Prim Care Respir Med. 2017; 27:28.

18. Mansi R, Joshi SV, Pandloskar SR, Dhar HL. Correlation Between Blood Sugar, Cholesterol and Asthma Status. Indian J Allergy Asthma Immunol. 2007; 21(1):31-34

19. Mostofizadeh N, Momen T, Saberi M, Reisi M, Hashemi E, Hashemipour $\mathrm{M}$ et al. The Prevalence of Asthma in Children under Eighteen Years Old with Type 1 Diabetes Mellitus and Relationship between Control of Diabetes and Severity of Asthma in 2016. Int J Pediatr. 2017; 5:7095-7102.

20. Ernst $P$, Suissa $S$. Systemic effects of inhaled corticosteroids. Curr Opin Pulm Med 2012; 18:85-89.

21. Derendof $H$, Nave R, Drollman A, Cerasoli F, Wurst W. Pharmacokinetic and pharmacodynamic properties of inhaled corticosteroids in relation to efficay and safety. Eur Respir J. 2006; 28: 1042-1050.

22. Köksal N,Büyükbeşe MA, Çetinkaya, İnanaç F. May Inhaled Corticosteroid Use Give Rise to Impaired Glucose Tolerance in Bronchial Asthma?. Dicle Med J. 2005; 32(1):26-30.

23. Faul JL, Wilson SR, Chu JW, Canfield J, Kuschner WG. The Effect of an Inhaled Corticosteroid on Glucose Control in Type 2 Diabetes. Clin Med Res. 2009; 7(1/2):14-20.

24. Blackburn D, Hux J, Mamdani M. Quanitification of the Risk of Corticosteroid-induced Diabetes Mellitus Among the Elderly. J Gen Intern Med. 2002; 17:717-720. 